\title{
ON THE ASYMPTOTIC STABILITY OF LINEAR DISCRETE TIME DELAY SYSTEMS
}

UDC 519.718:681.32

\author{
Sreten B. Stojanović ${ }^{1}$, Dragutin Lj. Debeljković ${ }^{2}$ \\ ${ }^{1}$ University of Niš, Faculty of Technology, Bulevar Oslobodjenja 124 \\ 16000 Leskovac, Serbia and Montenegro \\ ${ }^{2}$ University of Belgrade, Faculty of Mechanical Eng, Dept. of Control Eng., \\ 11000 Belgrade, Serbia and Montenegro
}

\begin{abstract}
This paper extends some of the basic results in the area of Lyapunov (asymptotic) to linear, discrete, time invariant time-delay systems. These results are given in the form of only sufficient conditions and represent another generalization of some previous or completely new results. In the latter case it is easy to show that, in most cases, these results are less conservative than those in existing literature.

A numerical example is worked out to show the applicability of results derived. To the best knowledge of the authors, such results have not been reported yet.
\end{abstract}

Key words: Linear Discrete Time Delay Systems, Lyapunov Stability.

\section{INTRODUCTION}

The problem of investigation of time delay systems has been exploited over many years.

Time delay is very often encountered in various technical systems, such as electric, pneumatic and hydraulic networks, chemical processes, long transmission lines, etc.

The existence of a pure time lag, regardless of whether it is present in the control or/and the state, may cause an undesirable system transient response, or even instability. Consequently, the problem of stability analysis for this class of systems has been one of the main interests for many researchers. In general, the introduction of time delay factors makes the analysis much more complicated.

In the existing stability criteria, mainly two ways of approach have been adopted.

Namely, one direction is to contrive the stability condition which does not include the information on the delay, and the other is the method which takes it into account. The former case is often called the delay - independent criteria and generally provides simple algebraic conditions.

Received January 10, 2004 
Numerous reports have been published in this matter, with a particular emphasis on the application of Lyapunov's second method or on using the concept of the matrix measure Lee, Diant (1981), Mori et al. (1981), Mori (1985), Hmamed (1986), Lee et al. (1986), Alastruey, De La Sen (1996).

The results concerning Lyapunov stability, for non delay time systems, are well documented in a number of known references but are omitted here for the sake of brevity.

Numerous results have been published in the context of finite and practical stability of linear continuous time delay systems, Nenadic et al. (1997), Debeljkovic et al. (1997a 1997d, 1998a -1998e).

The matrix measure approach was for the first time introduced in Debeljkovic et al. (1997b, 1997d), in investigation of Non- Lyapunov stability of this class of systems as well as the approach based on general application of the well known Bellman - Gronwall lemma, Lazarevic et al. (2000) to autonomous systems and to non-autonomous ones in Debeljkovic et al. (2000).

In this short overview, the results in the area of Lyapunov and Non-Lyapunov stability were only taken into consideration for continuous time delay systems.

Discussing the problem of investigation of linear discrete time delay systems and their Lyapunov stability it should be pointed out that there are not too many results dealing with this problem.

Namely, Koepcke (1965) was the first who paid attention to this class of systems solving a synthesis problem for control of the systems governed by linear differential difference equations. It has been shown, in the same paper, that such systems are equivalent to infinite dimensional difference equations whose matrix elements can be calculated readily by recursive formulas. Some results, concerning stability in the sense of Lyapunov, were also derived.

The problem of finding an optimal control in linear discrete systems with time delays in both the state variables and control were studied in Chung $(1967,1969)$.

The method of orthogonal projection was used to derive the equations for optimal estimates of the state of a non-stationary linear discrete system with multiple delays in Premier, Vacroux (1969). A Kalman - type filter with the necessary recursive error and cross error matrix equations was also derived.

The linear - quadratic tracking problem was discussed, for the first time, in Pindyck (1972), for discrete - time systems with the time delay incorporated in inputs.

A more general discussion concerning different aspects of continuous and discrete time delay systems can be found in Janusevski (1978), with particular attention paid to optimal control.

Several sufficient conditions for asymptotic stability of linear discrete - delay systems were presented in the paper of Mori et al. (1982). Since these conditions are independent of delay and since they possess simple forms, they provide useful tools to check system stability at the first stage.

The study of stabilization problem for general decentralized large - scale linear continuous and discrete time delay systems using local feedback controllers were presented by Lee, Radovic (1987). The local feedback controls were assumed to be memoryless. In that sense, the sufficient stabilization conditions were established.

The problem of delays in interconnections, for the same class of systems, was studied later in Lee, Radovic (1988). 
The paper of Trinh, Aldeen (1995) presents some new sufficient conditions for robust and D-stability of discrete - delay perturbed systems. It has been shown that these results are less conservative than those reported in literature, particularly in Mori et. al (1982).

Based on derived algebraic inequality, a criterion to guarantee the robust stabilization and state estimation for perturbed discrete- time -delay large scale systems was proposed in Wang, Mau (1995). That criterion is independent of time delay and does not need the solution of Lyapunov or Riccati equation.

The practical and finite time stability of linear discrete time delay systems was, for the first time, investigated in paper of Debeljkovic, Aleksendric (2003) and Debeljkovic et al. (2003).

In this paper the asymptotic stability of a particular class of the discrete time delay system is considered. Several sufficient conditions, in the form of time delayed independent criteria, are obtained.

The first group represents generalization of some previous results of Mori et. al (1992) and Trinith et. al (1995) referring to one delay cases only.

Another group, dealing with suitable decomposition of matrices, represents the main paper's contribution and is, at the same time, less restrictive than others given in recent literature.

\section{NOTATION AND PRELIMINARIES}

Let $|\mathbf{x}|_{(\cdot)}$ be any vector norm (e.g., $\left.\cdot=1,2, \infty\right)$ and $\|(\cdot)\|$ the matrix norm induced by this vector. Here, we use $|\mathbf{x}|_{2} \hat{=}\left(\mathbf{x}^{T} \mathbf{x}\right)^{1 / 2}$ and $\|(\cdot)\|_{2}=\lambda_{\text {max }}^{1 / 2}\left(A^{*} A\right)$. Upper indices $*$ and $T$ denote transpose conjugate and transpose, respectively. Absolute value of matrix $A$ is denoted by $|A|$, while $\rho(A)$ and $\operatorname{det}(A)$ mean spectral radius and determinant of matrix $A$.

$M$ denotes a class of real square matrices with non positive off-diagonal elements and positive principal minors.

A linear, autonomous, multivariable discrete time-delay system can be represented by the difference equation:

$$
\mathbf{x}(k+1)=A_{0} \mathbf{x}(k)+\sum_{j=1}^{N} A_{j} \mathbf{x}\left(k-h_{j}\right),
$$

where: $\mathbf{x}(k) \in \mathfrak{R}^{n}, A_{j} \in \mathfrak{R}^{n \times n}$ and $0=h_{0} \leq h_{1} \leq h_{2} \leq \ldots \leq h_{N}$ are integers and represent the systems time delays.

Preposition 1. Linear autonomous discrete time delay system (1) is asymptotically stable if and only if all his zeros of characteristic equation lie within the unit circle.

System (1) can be written in another way:

$$
\hat{\mathbf{x}}(k+1)=A_{e q} \hat{\mathbf{x}}(k),
$$

where:

$$
\hat{\mathbf{x}}(k)=\left[\begin{array}{llll}
\mathbf{x}(k) & \mathbf{x}(k-1) & \ldots & \mathbf{x}\left(k-h_{N}\right)
\end{array}\right]^{T} \in \mathfrak{R}^{n\left(h_{N}+1\right)},
$$




$$
\begin{aligned}
& A_{e q}=\left[\begin{array}{ccccc}
\hat{A}_{0} & \hat{A}_{1} & \ldots & \hat{A}_{h_{N}-1} & \hat{A}_{h_{N}} \\
I_{n} & 0 & \ldots & 0 & 0 \\
0 & I_{n} & \ldots & 0 & 0 \\
\ldots & \ldots & \ldots & \ldots & \ldots \\
0 & 0 & \ldots & I_{n} & 0
\end{array}\right] \hat{\mathbf{x}}(k)=\left[\begin{array}{llll}
\mathbf{x}(k) & \mathbf{x}(k-1) & \ldots & \mathbf{x}\left(k-h_{N}\right)
\end{array}\right]^{T} \in \mathfrak{R}^{n\left(h_{N}+1\right)} \\
& \hat{A}_{i}=\left\{\begin{array}{c}
A_{j}, \quad i=h_{j}, j=0,1, \ldots, N \\
0, \quad i \neq h_{j}, j=0,1, \ldots, N
\end{array}, \forall i=0,1, \ldots, h_{N} .\right.
\end{aligned}
$$

So necessary and sufficient conditions, for the asymptotic stability of (1) are:

$$
\operatorname{det}\left(z I_{n\left(h_{N}+1\right)}-A_{e q}\right) \neq 0, \quad|z| \geq 1 .
$$

Lemma 1. For any Hermite matrix $X \in \mathfrak{R}^{n \times n}$ and any complex vector $\mathbf{v} \in \mathfrak{R}^{n} /\{0\}$ it can be written:

$$
\lambda_{\min }(X) \leq \frac{\mathbf{v}^{*} X \mathbf{v}}{\mathbf{v}^{*} \mathbf{v}} \leq \lambda_{\max }(X),
$$

therefore, the lower and upper bound of this inequality can be reached if eigenvector $\mathbf{v}$ corresponds to eigenvalues $\lambda_{\min }(X)$, or $\lambda_{\max }(X)$, respectively. $\square$

Lemma 2. For any square matrix $X \in \mathfrak{R}^{n \times n}$ and any complex vector $\mathbf{v} \in \mathfrak{R}^{n} /\{0\}$, the field of values of:

$$
\frac{\mathbf{v}^{*} X \mathbf{v}}{\mathbf{v}^{*} \mathbf{v}}
$$

is always in the rectangle in the complex plane whose four vertices are given with:

$$
\left[\lambda_{i}(H), j \lambda_{k}(K)\right], i, k=\text { "min", "max", }
$$

where:

$$
H=\frac{1}{2}\left(X+X^{T}\right), \quad K=\frac{1}{2 j}\left(X-X^{T}\right), \quad j^{2} \hat{=}-1
$$

The matrix function:

$$
d(X) \hat{=} \max _{i, k} \sqrt{\lambda_{i}{ }^{2}(H(X))+\lambda_{k}{ }^{2}(K(X))}=\sqrt{\rho^{2}(H)+\rho^{2}(K)},
$$

represents the longest distance in complex plane between origin and the four points defined by (9). 


\section{MAIN RESUlts}

Theorem 1. System (1) is asymptotically stable if:

$$
\sum_{j=0}^{N}\left\|A_{j}\right\|<1
$$

Proof. The proof is based on contradiction.

Suppose that system to be considered is not stable which is equivalent to:

$$
\operatorname{det}\left(z I_{n}-A_{0}-\sum_{j=1}^{N} A_{j} z^{-h_{j}}\right)=0,|z| \geq 1
$$

or:

$$
\begin{gathered}
\exists \mathbf{v} \in ?^{n} \quad\left(z I_{n}-A_{0}-\sum_{j=1}^{N} A_{j} z^{-h_{j}}\right) \mathbf{v}=0,|z| \geq 1, \\
A_{0} \mathbf{v}=\left(z I_{n}-\sum_{j=1}^{N} A_{j} z^{-h_{j}}\right) \mathbf{v},|z| \geq 1, \\
\left\|A_{0}\right\|\|\mathbf{v}\| \geq\left\|A_{0} \mathbf{v}\right\|=\left\|\left(z I_{n}-\sum_{j=1}^{N} A_{j} z^{-h_{j}}\right) \mathbf{v}\right\| \geq|z|\|\mathbf{v}\|-\left\|\sum_{j=1}^{N} z^{-h_{j}} A_{j} \mathbf{v}\right\| \\
\geq|z|\|\mathbf{v}\|-\sum_{j=1}^{N}\left|z^{-h_{j}}\right|\left\|A_{j}\right\|\|\mathbf{v}\| \geq\|\mathbf{v}\|\left(1-\sum_{j=1}^{N}\left\|A_{j}\right\|\right),|z| \geq 1 .
\end{gathered}
$$

So if the system is not stable, then:

$$
\sum_{j=0}^{N}\left\|A_{j}\right\| \geq 1
$$

This is in contradiction, so the system under consideration is stable.

Conclusion 1. If $N=1$, condition (12) is reduced to condition given in Mori (1982).

Theorem 2. System, (1) is asymptotically stable if the following condition is satisfied:

$$
\sum_{j=0}^{N} d\left(A_{j}\right)<1,
$$

where matrix function $d($.$) is given with (11).$

Proof. Proof is based on contradiction.

Suppose that the system under consideration is not stable, which is equivalent to:

$$
\operatorname{det}\left(z I_{n}-A_{0}-\sum_{j=1}^{N} A_{j} z^{-h_{j}}\right)=0,|z| \geq 1,
$$


so:

$$
\begin{gathered}
\exists \mathbf{v} \in ?^{n} \quad\left(z I_{n}-A_{0}-\sum_{j=1}^{N} A_{j} z^{-h_{j}}\right) \mathbf{v}=0,|z| \geq 1, \\
A_{0} \mathbf{v}=\left(z I_{n}-\sum_{j=1}^{N} A_{j} z^{-h_{j}}\right) \mathbf{v},|z| \geq 1, \\
\mathbf{v}^{*} A_{0} \mathbf{v}=\mathbf{v}^{*}\left(z I_{n}-\sum_{j=1}^{N} A_{j} z^{-h_{j}}\right) \mathbf{v},|z| \geq 1, \\
\left|\mathbf{v}^{*} A_{0} \mathbf{v}\right|=\left|\mathbf{v}^{*}\left(z I_{n}-\sum_{j=1}^{N} A_{j} z^{-h_{j}}\right) \mathbf{v}\right| \geq\left|\mathbf{v}^{*} z \mathbf{v}\right|-\left|\sum_{j=1}^{N} \mathbf{v}^{*} A_{j} z^{-h_{j}} \mathbf{v}\right| \\
\geq\left|\mathbf{v}^{*} z \mathbf{v}\right|-\sum_{j=1}^{N}\left|\mathbf{v}^{*} A_{j} z^{-h_{j}} \mathbf{v}\right| \geq|z|\left|v^{*} v\right|-\left|z^{-h_{j}}\right| \sum_{j=1}^{N}\left|v^{*} A_{j} v\right| \geq \mathbf{v}^{*} \mathbf{v}-\sum_{j=1}^{N}\left|\mathbf{v}^{*} A_{j} \mathbf{v}\right|,|z| \geq 1, \\
\sum_{j=0}^{N} \frac{\left|\mathbf{v}^{*} A_{j} \mathbf{v}\right|}{\mathbf{v}^{*} \mathbf{v}} \geq 1 .
\end{gathered}
$$

Based on Lemma 2:

$$
1 \leq \sum_{j=0}^{N} \frac{\left|\mathbf{v}^{*} A_{j} \mathbf{v}\right|}{\mathbf{v}^{*} \mathbf{v}} \leq \sum_{j=0}^{N} d\left(A_{j}\right),
$$

which is in contradiction with the condition of Theorem. So if inequality (18) is satisfied, then system under consideration is asymptotically stable.

Conclusion 2. If $N=1$, from (18) follows condition given in Mori (1982).

Theorem 3. If matrix $D$, defined with:

$$
\begin{gathered}
D \hat{=} I_{n}-\sum_{j=0}^{N}\left|A_{j}\right|, \\
d_{i k} \hat{=}=\left\{\begin{array}{l}
d_{i i}=1-\sum_{j=0}^{N}\left|a_{i i}^{j}\right| \\
d_{i k}=-\sum_{j=0}^{N}\left|a_{i k}^{j}\right|
\end{array}\right.
\end{gathered}
$$

belongs to $M$ - class of matrices, then system (1) is asymptotically stable. $\square$

Proof. Characteristic matrix $F(z)$, for system (1), is defined with:

$$
F(z) \hat{=} z I_{n}-\sum_{j=0}^{N} A_{j} z^{-h_{j}}=\left\{f_{i k}\right\} .
$$

Elements of matrix $F(\mathrm{z})$ fulfill: 


$$
\begin{gathered}
\left|f_{i i}\right|=\left|z-\sum_{j=0}^{N} a_{i i}^{j} z^{-h_{j}}\right| \geq|z|-\sum_{j=0}^{N}\left|a_{i i}^{j}\right|\left|z^{-h_{j}}\right| \geq 1-\sum_{j=0}^{N}\left|a_{i i}^{j}\right|=d_{i i},|z| \geq 1, \\
\left|f_{i k}\right|=\left|-\sum_{j=0}^{N} a_{i k}^{j} z^{-h_{j}}\right| \leq \sum_{j=0}^{N}\left|a_{i k}^{j}\right|\left|z^{-h_{j}}\right| \leq \sum_{j=0}^{N}\left|a_{i k}^{j}\right|=-d_{i k} \geq 0, \quad|z| \geq 1 .
\end{gathered}
$$

Since matrix $D$ belongs to $M$-class of matrices $\left(d_{i k} \leq 0\right.$, det $\left.D>0\right)$, it follows:

$$
\begin{gathered}
|\operatorname{det} F(\mathrm{z})| \geq \operatorname{det} D,|z| \geq 1, \\
\operatorname{det} F(\mathrm{z}) \neq 0,|z| \geq 1 .
\end{gathered}
$$

The last expression shows that there exists no root of the characteristic equation of system under consideration lying in right half of complex plane, so this system is asymptotically stable.

Conclusion 3. From basic condition of Theorem 3, for $N=1$, follows condition given in Mori et. al (1982).

Lemma 3. Matrix $D \in R^{n \times n}$ belongs to $M$-class of matrices if and only if:

$$
\exists C \in \mathfrak{R}^{n \times n} \geq 0 \quad \exists r \in \mathfrak{R}>\rho(C) \quad D=r I_{n}-C .
$$

Conclusion 4. If one uses norm, $\|(\cdot)\|_{(\cdot),}(\cdot)=1, \infty$, in Theorem 1 , then:

$$
1>\sum_{j=0}^{N}\left\|A_{j}\right\|_{(\bullet)}=\sum_{j=0}^{N}\left\|\left|A_{j}\right|\right\|_{(\bullet)} \geq\left\|\sum_{j=0}^{N}\left|A_{j}\right|\right\|_{(\bullet)} \geq \rho\left(\sum_{j=0}^{N}\left|A_{j}\right|\right) .
$$

If one defines:

$$
\begin{gathered}
C=\sum_{j=0}^{N}\left|A_{j}\right| \geq 0, \\
r=1>\rho\left(\sum_{j=0}^{N}\left|A_{j}\right|\right)=\rho(C), \\
D=I_{n}-\sum_{j=0}^{N}\left|A_{j}\right|,
\end{gathered}
$$

then we can conclude from Lemma 3 that matrix $D$ belongs to $M$-class of matrices.

This shows that Theorem 1 implies Theorem 3 and the condition of Theorem 1 is more restrictive than the condition of Theorem 3 when $\|(\cdot)\|=\|(\cdot)\|_{1}$ or $\|(\cdot)\|_{\infty}$. 
Theorem 4. System (1) is asymptotically stable, if one of these two conditions is satisfied:

$$
\begin{aligned}
& \sum_{j=0}^{N} \rho\left(H_{j}\right)<1, \\
& \sum_{j=0}^{N}\left\|H_{j}\right\|_{2}<1,
\end{aligned}
$$

where matrices $H_{j}$ are defined with:

$$
H_{j}=\frac{A_{j}+A_{j}{ }^{T}}{2}, j=0,1, \ldots, N
$$

Proof. The proof is based on contradiction.

Suppose that the system to be considered is not stable. Like with the proof of Theorem 2, we have:

$$
\sum_{j=0}^{N} \frac{\left|\mathbf{v}^{*} A_{j} \mathbf{v}\right|}{\mathbf{v}^{*} \mathbf{v}} \geq 1
$$

It should be noted that every square matrix $X$ can be expressed in the following way:

$$
X=\frac{X+X^{T}}{2}+j \frac{X-X^{T}}{2 j}=H+j K .
$$

If matrix $X$ is a real square matrix, then matrixes $H$ and $K$ are symmetric and Hermite matrices and we get:

$$
\begin{gathered}
\lambda_{\text {min }}(H) \leq \frac{\mathbf{v}^{*} H \mathbf{v}}{\mathbf{v}^{*} \mathbf{v}}=\frac{\mathbf{v}^{*} X \mathbf{v}}{\mathbf{v}^{*} \mathbf{v}} \leq \lambda_{\text {max }}(H), \\
\frac{\mathbf{v}^{*} K \mathbf{v}}{\mathbf{v}^{*} \mathbf{v}}=0,
\end{gathered}
$$

as well as:

$$
\frac{\left|\mathbf{v}^{*} X \mathbf{v}\right|}{\mathbf{v}^{*} \mathbf{v}} \leq \max \left[\left|\lambda_{\min }(H)\right|,\left|\lambda_{\max }(H)\right|\right]=\underset{i}{\max }\left|\lambda_{i}(H)\right|=\rho(H)
$$

Applying the last inequality to (41), one can get:

$$
1 \leq \sum_{j=0}^{N} \frac{\left|\mathbf{v}^{*} A_{j} \mathbf{v}\right|}{\mathbf{v}^{*} \mathbf{v}} \leq \sum_{j=1}^{N} \rho\left(H_{j}\right)
$$

which is in contradiction with the condition of Theorem.

So if inequality (38) is satisfied, then system under consideration is asymptotically stable. 
Condition (39) follows directly from (38), having in mind that matrices $H_{j}$ are symmetric, so it may be written:

$$
\rho\left(H_{j}\right)=\left\|H_{j}\right\|_{2}, j=0,1, \ldots, N .
$$

Conclusion 5. On the basis of elementary algebra the following conditions are fulfilled:

$$
\begin{gathered}
\rho(A)=\rho(H+j K)=\max _{i}\left|\lambda_{i}(H+j K)\right| \leq \max _{i}\left|\lambda_{i}(H)+j \lambda_{i}(K)\right| \\
\leq \max _{i}\left|\lambda_{i}(H)\right|+\max _{i}\left|j \lambda_{i}(K)\right|=\rho(H)+\rho(K)=\|H\|_{2}+\|K\|_{2}, \\
\rho(H)=\|H\|_{2}=\frac{1}{2}\left\|A+A^{T}\right\|_{2} \leq \frac{1}{2}\left(\|A\|_{2}+\left\|A^{T}\right\|_{2}\right)=\|A\|_{2} .
\end{gathered}
$$

From Bendixson's inequality,

$$
\begin{aligned}
& \lambda_{\text {min }}(H) \leq \operatorname{Re} \lambda(A) \leq \lambda_{\text {max }}(H), \\
& \lambda_{\text {min }}(K) \leq \operatorname{Im} \lambda(A) \leq \lambda_{\text {max }}(K),
\end{aligned}
$$

it follows:

$$
\begin{gathered}
|\lambda(A)| \leq \sqrt{\lambda_{H}{ }^{2}+\lambda_{K}{ }^{2}}, \\
\lambda_{H}=\max \left\{\left|\lambda_{\text {min }}(H)\right|,\left|\lambda_{\text {max }}(H)\right|\right\}=\max _{i}\left|\lambda_{i}(H)\right|=\rho(H), \\
\lambda_{K}=\max \left\{\left|\lambda_{\text {min }}(K)\right|,\left|\lambda_{\text {max }}(K)\right|\right\}=\max _{i}\left|\lambda_{i}(K)\right|=\rho(K),
\end{gathered}
$$

and finally:

$$
\max _{i}\left|\lambda_{i}(A)\right|=\rho(A) \leq \sqrt{\rho^{2}(H)+\rho^{2}(K)} \hat{=} d(A) .
$$

So from (49) and (54), it follows:

$$
\rho(H)=\|H\|_{2} \leq d(A), \rho(H)=\|H\|_{2} \leq\|A\|_{2} .
$$

Conclusion 6. It is not difficult to prove, having in mind (55) that the following expressions are valid:

$$
\sum_{j=0}^{h_{N}} \rho\left(H_{j}\right) \leq \sum_{j=0}^{h_{N}} d\left(A_{j}\right)<1, \sum_{j=0}^{h_{N}}\left\|H_{j}\right\|_{2} \leq \sum_{j=0}^{h_{N}}\left\|A_{j}\right\|<1,
$$

therefore, the conditions given Theorem 1 and Theorem 2 are more restrictive than those given in Theorem 4.

According to the sufficient conditions, given here with (38-39), one can conclude:

- Simple for use since only the matrix norms are used.

- The solutions are less restrictive comparing to those given by conditions (12) and (18), which represent the generalization of conditions proposed by Mori (1982). 
Lemma 4. Trinth et al. (1995).

Let:

$$
G(z) \hat{=}\left(z I_{n}-A\right)^{-1},
$$

then:

$$
\left|G(z) z^{-h}\right| \leq \sum_{k=0}^{\infty}|G(k)| \hat{=} L,|z| \geq 1,
$$

$G(k)$ is the pulse - response sequence matrix of $G(z)$ and $G(0)=0$.

Lemma 5. Trinth et al. (1995).

For any $(n \times n)$ square matrix $X$, the following statement is true:

$$
\rho(X)<1 \Rightarrow \operatorname{det}\left(I_{n}-X\right) \neq 0 \text {. }
$$

Lemma 6. For any square matrices $X \in \mathfrak{R}^{n \times n}$ and $Y \in \mathfrak{R}^{n \times n}$, the following statement is true:

$$
|X| \leq Y \Rightarrow \rho(X) \leq \rho(|X|) \leq \rho(Y)
$$

Theorem 5. System (1) is asymptotically stable, independent of delay, if the following conditions are satisfied:

$$
\begin{gathered}
\rho\left(A_{0}\right)<1, \\
\rho\left(L \sum_{j=1}^{N}\left|A_{j}\right|\right)<1,
\end{gathered}
$$

where $L$ is defined as in (58), and $G(k)$ is obtained from:

$$
G(k)=A_{0}^{k-1}, \quad k=1,2, \ldots, \infty, \quad G(0)=0 .
$$

Proof. Suppose that system (1) is asymptotically stable.

The following conditions are equivalent to the previous one:

$$
\begin{gathered}
\operatorname{det}\left(z I_{n}-A_{0}-\sum_{j=1}^{N} A_{j} z^{-h_{j}}\right) \neq 0,|z| \geq 1, \\
\operatorname{det}\left(\left(z I_{n}-A_{0}\right)\left[I_{n}-\left(z I_{n}-A_{0}\right)^{-1} \sum_{j=1}^{N} A_{j} z^{-h_{j}}\right]\right) \neq 0,|z| \geq 1, \\
\operatorname{det}\left(z I_{n}-A_{0}\right) \operatorname{det}\left(I_{n}-G(z) \sum_{j=1}^{N} A_{j} z^{-h_{j}}\right) \neq 0,|z| \geq 1,
\end{gathered}
$$

where: $G(z)=\left(z I_{n}-A_{0}\right)^{-1}$. Since $A_{0}$ is a discrete stable matrix: $\operatorname{det}\left(z I_{n}-A_{0}\right) \neq 0,|\mathrm{z}| \geq 1$, so the last condition is equivalent to: 


$$
\operatorname{det}\left(I_{n}-G(z) \sum_{j=1}^{N} A_{j} z^{-h_{j}}\right) \neq 0,|z| \geq 1
$$

Using Lemma 5, one can get:

$$
\rho\left(G(z) \sum_{j=1}^{N} A_{j} z^{-h_{j}}\right)<1,|z| \geq 1
$$

Based on Lemma 4 and Lemma 6, we have:

$$
\rho\left(G(z) \sum_{j=1}^{N} A_{j} z^{-h_{j}}\right) \leq \rho\left(\left|G(z) \sum_{j=1}^{N} A_{j} z^{-h_{j}}\right|\right) \leq \rho\left(|G(z)| \sum_{j=1}^{N}\left|A_{j} \| z^{-h_{j}}\right|\right) \leq \rho\left(L \sum_{j=1}^{N}\left|A_{j}\right|\right),|z| \geq 1
$$

If the following inequality is fulfilled:

$$
\rho\left(L \sum_{j=1}^{N}\left|A_{j}\right|\right)<1
$$

then inequality (67) is satisfied as well, so the system under consideration is asymptotically stable.

Conclusion 7. Fundamental matrix of system (1) without delay is:

$$
\Phi(z)=\left(z I_{n}-A_{0}\right)^{-1} z=G(z) z
$$

so:

$$
G(z)=z^{-1} \Phi(z) \Rightarrow G(k)=\Phi(k-1)=A_{0}^{k-1}, \quad G(0)=0
$$

If $A_{0}$ is a discrete stable matrix, $\rho\left(A_{0}\right)<1$, then infinite series:

$$
L=\sum_{k=0}^{\infty}|G(k)|=\sum_{k=1}^{\infty}|G(k)|=\sum_{k=0}^{\infty}\left|A_{0}^{k}\right| \leq \sum_{j=0}^{\infty}\left|A_{0}\right|^{k}=\left(I_{n}-\left|A_{0}\right|\right)^{-1}
$$

is convergent, so one can find matrix $L$ by direct computation.

Conclusion 8. Conditions (61) are less restrictive than condition (12).

The reason is in the fact that conditions (61) take into account the matrix time delay structure $A_{j}$, where as condition (12) takes only the norm of matrices.

Example 1. Consider the discrete time delay system:

where:

$$
x(k+1)=A_{0} x(k)+A_{1} x(k-1)+A_{2} x(k-2),
$$

$$
A_{0}=\left[\begin{array}{cc}
0.2 & 0.3 \\
0.1 & -0.15
\end{array}\right], A_{1}=\gamma\left[\begin{array}{cc}
0.3 & 0 \\
0.2 & 0.1
\end{array}\right], A_{2}=\left[\begin{array}{cc}
0.1 & 0.2 \\
0.15 & 0.1
\end{array}\right],
$$

and $\gamma$ - is parameter. 
Applying all of the Theorems derived, the conditions for the asymptotic stability are shown in the following Table:

\begin{tabular}{|c|c|c|c|c|}
\hline Theorem 1 & Theorem 2 & Theorem $\mathbf{3}$ & Theorem 4 & Theorem $\mathbf{5}$ \\
\hline \multirow{2}{*}{$\sum_{j=0}^{N}\left\|A_{j}\right\|<1$} & \multirow{2}{*}{$\sum_{j=0}^{N} d\left(A_{j}\right)<1$} & \multirow{2}{*}{$\begin{aligned} D & \hat{=} I_{n}-\sum_{j=0}^{N}\left|A_{j}\right| \\
& \text { is M-matrix }\end{aligned}$} & $\sum_{j=0}^{N} \rho\left(H_{j}\right)<1$ & \multirow{2}{*}{$\rho\left(L \sum_{j=1}^{N}\left|A_{j}\right|\right)<1$} \\
\hline & & & $\sum_{j=0}^{N}\left\|H_{j}\right\|_{2}<1$ & \\
\hline $\begin{array}{c}\|(\cdot)\|_{1}:|\gamma|<0.5 \\
\|(\cdot)\|_{2}:|\gamma|<0.9673 \\
\|(\cdot)\|_{\infty}:|\gamma|<0.6667\end{array}$ & $|\gamma|<1.1704$ & $|\gamma|<1.1055$ & $|\gamma|<1.2719$ & $|\gamma|<1.2440$ \\
\hline
\end{tabular}

On the basis of the results collected in Table one can conclude the following:

- The results of Theorem 4 are less restrictive than Theorems 1 and 2, as was proved in Conclusion 6.

Since conditions of Theorems 1 and 2, in the cases of systems with only one time delay, are reduced to the results given in Mori et al. (1982), it follows that conditions of

Theorem 4 are less restrictive than the corresponding ones given in Mori et al. (1982).

- The best result is achieved using Theorem 4 and then using Theorem 5.

- Condition given by Theorem 4 is very simple for numerical computation.

If one adopts $\gamma=1.2719$, then spectral radius of equivalent matrix $A_{e q}$ of system without time delay is $\rho\left(A_{e q}\right)=0.9823$.

Since it is less than one, the result from Table guarantees the asymptotic stability of system under consideration.

The upper bound for parameter value $\gamma$ is 1.3746 and the system is marginally stable, so the presented discussion is logical.

\section{CONCLUSION}

In this paper we have presented some new criteria for testing the asymptotic stability of linear discrete time delay systems.

All the conditions are in the form of only sufficient conditions and belong to so-called independent delay criteria.

Discussions of conservatism of results are also attached.

All the results derived are supported by suitable examples, showing the advantages of different approaches to the given problem. 


\section{REFERENCES}

1. Debeljkovic D. Lj., Nenadic Z. Lj., Milinkovic S. A. and Jovanovic M. B. (1997a), "On Practical and Finite-time Stability of Time-delay Systems", Proc. ECC97, Brussels (Belgium), pp. 307-311.

2. Debeljkovic D. Lj., Nenadic Z. Lj., Koruga Dj., Milinkovic S. A. and Jovanovic M. B., (1997b), "On Practical Stability of Time-delay Systems: New Results ", Proc. 2nd ASCC 97, Seoul (Korea), pp. III543-546.

3. Debeljkovic D. Lj., Lazarevic M. P., Koruga Dj. and Tomasevic S., (1997c), "On Practical Stability of Time Delay System under Perturbing Forces ", Proc. AMSE 97, Melbourne (Australia), pp. 442-446.

4. Debeljkovic D. Lj., Nenadic Z. Lj., Milinkovic S. A and Jovanovic M. B. (1997d), "On the Stability of Linear Systems with Delayed State Defined over Finite Time Interval ", Proc. CDC 97, San Diego, California (USA), pp. 2771-2772.

5. Debeljkovic D. Lj., Koruga Dj., Milinkovic S. A., Jovanovic M. B. and Jacic Lj. A, (1998a), "Further Results on Non - Lyapunov Stability of Time Delay Systems", Proc. MELECON 98, Tel - Aviv (Israel), May 18-20, Vol.1, pp. 509-512.

6. Debeljkovic D. Lj., Koruga Dj., Milinkovic S. A. and Jovanovic M. B., (1998b), "Non - Lyapunov Stability Analysis of Linear Time Delay Systems", Preprints DYCOPS 5, 5th IFAC Symposium on Dynamics and Process Systems, Corfu (Greece), June 8 - 10, , pp. 549 - 553.

7. Debeljkovic D. Lj., Lazarevic M. P., Milinkovic S. A. and Jovanovic M. B., (1998c), "Finite Time Stability Analysis of Linear Time Delay Systems: Bellman - Gronwall Approach", Preprints IFAC Workshop on Linear Time Delay Systems, Grenoble (France), July 6-7, pp.107-112.

8. Debeljkovic D. Lj., Milinkovic S. A., Jovanovic M. B., Jacic Lj. A. and Koruga Dj., (1998d), "Finite Time Stability of Linear Discrete Descriptor Systems", Preprints 5th IFAC Symposium on Low Cost Automation, Shenyang (China), September 8 - 10 pp. TS13 1 - 5 .

9. Debeljkovic, D. Lj., Milinkovic S. A., Jovanovic M.B., Jacic Lj. A. and Koruga Dj., (1998e),"Further Results on Non - Lyapunov Stability of Time Delay Systems", Preprints 5th IFAC Symposium on Low Cost Automation, Shenyang (China), September 8 - 10 pp. TS13 6 - 10

10. Debeljkovic, D. Lj., Lazarevic M. P., Koruga Dj., Milinkovic S. A. and Jovanovic M.B., (2000), "Further Results on the Stability of Linear Nonautonomous Systems with Delayed State Defined over Finite Time Interval", Proc. APCCM, 9 - 12 July, Guilin (China), pp. D.9.

11. Debeljkovic, D. Lj. and Aleksendric M., (2003), "Lyapunov and Non-Lyapunov of Linear Discrete Time Delay Systems", Proc. ACC 2003, Denver, Colorado, (USA), FM05-1, CD-Rom, pp...(accepted).

12. Debeljkovic D. Lj., Aleksendric M., Yong N. Y. and Zhang Q. L., (2003), "Lyapunov and NonLyapunov of Linear Discrete Time Systems with Delayed State", Proc. ICCA 2003, Montreal, (Canada), CD-Rom, pp...(accepted).

13. Koepcke, R. W., "On the Control of Linear Systems with Pure Time Delay ", (1965) Trans. ASME J. Basic Eng., (3) 74-80, 1965.

14. Januševskii, R. T., Upravlenie objektami s zapazdavanijem, Nauka, Moskva, 1978.

15. Lazarevic, M. P., Debeljkovic D. Lj., Nenadic Z. Lj. and Milinkovic S. A., (1999), " Finite Time Stability of Time Delay Systems", IMA Journal of Mathematical Control and Information, Vol. 17, No.3, pp. $101-109$.

16. Lee T. and Radovic U., (1987), "General Decentralized Stabilization of Large-scale Linear Continuous and Discrete Time-delay Systems", Int. J. Control 46 (6) 2127-2140.

17. Lee T. and Radovic U., (1988), "Decentralized Stabilization of Linear Continuous and Discrete-Time Systems with Delays in Interconnections", IEEE Trans. Automat. Control, AC-33 (8) 757-761.

18. Mori, T., Fukuma N. and Kuwahara M., (1982), "Delay - Independent Stability Criteria for Discrete Delay Systems", IEEE Trans. Automat. Contr., AC-27 (4) 946-966.

19. Nenadc, Z. Lj., Debeljkovic D. Lj. and Milinkovic S.A., (1997), "On Practical Stability of Time Delay Systems", Proc. AACC, Alberquerque, New Mexico, (USA), June 4 - 6, 3235 - 3236.

20. Trinh H. and Aldeen M., (1995a), "D-Stability Analysis of Discrete-Delay Perturbed Systems", Int. J. Control 61 (2) 493-505.

21. Trinh H. and Aldeen M., (1995b), "Robust Stability of Singularly Perturbed Discrete-Delay Systems", IEEE Trans. Automat. Contr., AC-40 (9) 1620-1623.

22. Trinh H. and Aldeen M., (1997), "A Memoryless State Observer for Discrete Time - Delay Systems", IEEE Trans. Automat. Contr. AC-42 (11) 1572-1577.

23. Wang W. and Mau L., (1997), "Stabilization and Estimation for Perturbed Discrete Time-Delay Large Scale Systems", IEEE Trans. Automat. Contr., AC-42 (9) 1277-1282. 


\section{ASIMPTOTSKA STABILNOST LINEARNIH DISKRETNIH SISTEMA SA ČISTIM VREMENSKIM KAŠNJENJEM}

\section{Sreten B. Stojanović, Dragutin Lj. Debeljković}

Ovaj rad proširuje neke bazične rezultate iz teorije Ljapunovske stabilnosti na posebnu klasu linearnih vremenski diskretnih stacionarnih sistema sa čistim vremenskim kašnjenjem. Izvedeni rezultati dati su u formi dovoljnih uslova i u izvesnom smislu predstavljaju generalizaciju nekih ranijih rezultata poznatih iz literature ili potpuno nove. $U$ ovom poslednjem slučaju lako se pokazuje, u većini slučajeva, da se dobijaju rezultati koji su manje konzervativniji od postojećih.

Kroz numeričke primere ilustrovana primenljivost $i$ efikasnost izloženih rezultata.

Ključne reči: linearni vremenski diskretni stacionarni sistemi, Ljapunovska stabilnost. 